\section{A pesquisa científica e a gestão ambiental no Parque Martírios-Andorinhas}

\author{
Por Regina Oliveira da Silva \\ Doutora em Desenvolvimento Sustentável e \\ Política Ambiental pela Universidade de Brasilia. \\ Pesquisadora do Museu Paraense Emílio Goeldi/MCT \\ (oliveira@museu-goeldi.br)
}

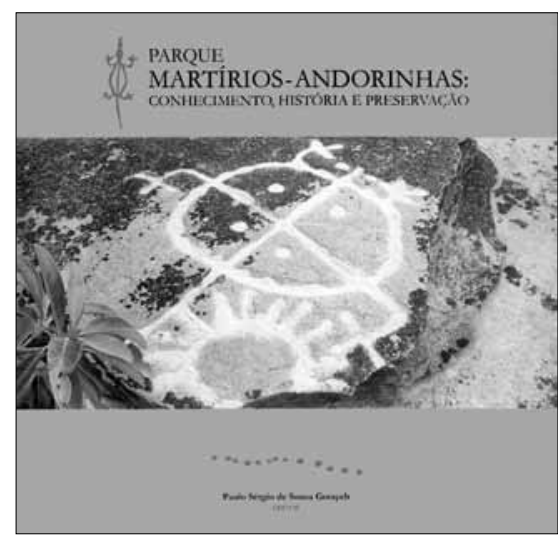

GORAYEB, Paulo Sérgio de Sousa (Org.).

Parque MartíriosAndorinhas: conhecimento, história e preservação. Belém: EDUFPA, 2008. 353p. ISBN 978-8524703-92-8

O livro "Parque Martírios-Andorinhas: conhecimento, história e preservação", editado pelo professor Paulo Sérgio de Sousa Gorayeb, é o resultado de um projeto que reuniu pesquisadores de distintas linhas para descrever cientificamente diferentes aspectos da região do Parque Estadual da Serra dos Martírios-Andorinhas, no município de São Geraldo do Araguaia, Pará. O Parque é circundado pela Área de Proteção Ambiental de São Geraldo do Araguaia e ambas as unidades de conservação foram criadas em 1996. Com cerca de 25 mil hectares, o Parque está localizado nas margens do rio Araguaia, sudeste do Pará. A região está inserida no chamado 'Arco do Desflorestamento'. Foi o segundo Parque Estadual criado no Pará.

A Serra dos Martírios, rebatizada de Serra das Andorinhas após a Guerrilha do Araguaia, é um dos cenários amazônicos onde a história antiga e contemporânea se cruzaram em prol da liberdade e da conservação da biodiversidade. A origem do nome remete aos bandeirantes, que, em busca das "preciosidades do sertão", associaram os desenhos rupestres aos símbolos cristãos utilizados no martírio de Cristo (ver páginas 38 e 132). A região abriga uma diversidade biológica e cultural representada pela flora e fauna, pelos sítios arqueológicos e pela arte rupestre de relevância, que se cristalizou na criação de duas unidades de conservação: uma de proteção integral e outra de uso sustentável.

O livro contém 17 artigos e reuniu 43 autores, entre pesquisadores, professores e alunos de pósgraduação, assim como representantes de organizações da sociedade civil. Nos textos que descrevem os resultados das investigações científicas, encontramos rica exposição de fotos da região, mapas e imagens que divulgam os exuberantes ecossistemas, as moradias de povos antigos e o palco da Guerrilha do Araguaia. Trata-se de um livro de divulgação científica elaborado de forma a atender aos leitores interessados nesta categoria de informação.

Alguns artigos resultaram de uma proposta de pesquisa realizada em duas etapas compreendidas no período de 1998 a 2002, quando pesquisadores de diferentes instituições integraram conhecimentos a fim de subsidiar os gestores do Estado nas questões ambientais pertinentes ao recém criado Parque Estadual da Serra dos Martírios-Andorinhas. Os resultados descritos no livro tiveram como meta, já em 1998, iniciar a elaboração do plano de manejo, gerando conhecimento sobre a área e visando à gestão das unidades de conservação.

A sequência dos textos remete ao antigo roteiro metodológico do Instituto Brasileiro do Meio Ambiente e dos Recursos Naturais Renováveis (IBAMA) para a elaboração de planos de manejo. Descreve fisicamente a região, os solos, as cavernas, a hidrologia e, sequencialmente, os textos apresentam informações sobre a flora e a fauna, finalizando com a descrição de aspectos antrópicos. Ressalta-se que esta iniciativa foi pioneira no estado do Pará, visto que a proposição de estratégias para a conservação, resultantes de estudos interdisciplinares e multinstitucionais, não fazia parte das políticas ambientais da época.

Os dois primeiros textos tratam da história da região e da criação do Parque. Permitem ao leitor entender a importância da área para a conservação da biodiversidade,

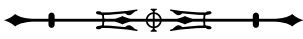


visto que foram escritos por gestores. $\bigcirc$ conteúdo traz informações preciosas sobre o processo de criação de unidades de conservação e sobre os encaminhamentos da política ambiental vigente na época, associadas aos resultados do recente plano de manejo elaborado para o Parque. O histórico da região da Serra das Andorinhas percorre uma viagem a partir do século XVII, quando os bandeirantes se deslocam pela Amazônia e seus registros atraem os coletores de 'drogas do sertão'. Nos séculos posteriores, as localidades e os sítios rupestres, assim como o rio Araguaia, são palcos de novas investidas para estudos e descobertas de naturalistas e exploradores, como o casal Coudreau e o antropólogo alemão Paul Ehrenreich. Evidentemente, a Guerrilha do Araguaia compõe este capítulo com uma descrição da história recente do país.

Os textos seguintes discorrem sobre os aspectos físicos do Parque da Serra das Andorinhas, descrevendo a geologia, a geomorfologia, os minerais e as cavernas. Os textos são técnicos e com certa limitação para o entendimento de leigos no assunto. No entanto, a riqueza das ilustrações e dos mapas permite aos interessados neste tema uma viagem à região. A descrição dos minerais e das cavernas auxilia a compreender a importância histórica do Parque para os antigos viajantes, quando a busca pelo ouro e outras preciosidades minerais dominou as expedições. As características únicas das formações geológicas e geomorfológicas da área ganham nominações locais.

O final da descrição dos aspectos históricos e físicos do Parque apresenta textos sobre a arqueologia e a hidrografia. Estes artigos merecem uma leitura atenciosa, visto que destacam a importância de salvaguardar a história da ocupação humana e de conservar um recurso altamente vulnerável na Amazônia. Os estudos arqueológicos na região do Parque foram iniciados pela Fundação Casa da Cultura de Marabá, organização com grande atuação na região e que chamou a atenção para a preservação da área. A parceria com pesquisadores do Museu Paraense Emílio Goeldi potencializou as pesquisas arqueológicas, sobretudo, no que se refere aos estudos de material cerâmico e lítico.
Durante o projeto de pesquisa, foram localizados 80 sítios arqueológicos na região da Serra das Andorinhas. Os painéis e abrigos com gravuras rupestres estão ilustrados no livro e comprovam o valioso acervo cultural do Parque.

$\bigcirc$ artigo que trata da hidrografia também inseriu dados referentes à climatologia. $\bigcirc$ texto discorre sobre as características climáticas da região e sua classificação de acordo com a localização geográfica das bacias dos rios Araguaia e Tocantins. $O$ estudo foi realizado na microbacia do ribeirão Sucupira, considerado importante para a manutenção dos ecossistemas do Parque. No artigo, a autora propõe o manejo desta microbacia e destaca as vulnerabilidades naturais para a manutenção dos ecossistemas, visto que a região está localizada em uma área de transição entre a floresta amazônica e o cerrado, dois dos biomas brasileiros mais ameaçados.

Os artigos seguintes levam o leitor a conhecer alguns aspectos da biodiversidade do Parque. Nos estudos da vegetação, o foco foi dado às áreas de cerrado, que predominam no interior do Parque. Foi estudada também a floresta submontana. A caracterização e a importância biológica ganham destaque no texto, assim como uma breve contextualização fitogeográfica. Os autores chamam a atenção para a exploração de orquídeas na região, assim como para as medidas de integração das políticas de conservação no âmbito estadual e federal, visando à mitigação do desmatamento.

Os artigos que descrevem a fauna local dão ênfase aos artrópodes, com minuciosa descrição dos pertencentes às ordens Diptera (Tabanidae e Simuliidae) e Coleoptera. São estudos de coleta e identificação das espécies que ocorrem na região do Parque. Os resultados justificam o empenho nestas pesquisas e a importância da conservação da área, visto que os sete mil exemplares de artrópodes mereceram uma coleção específica (ver páginas 207 e 208). Embora com resultados ainda preliminares, os autores destacam a importância deste filo para a manutenção dos processos ecológicos locais e para o manejo do Parque.

Os quirópteros também foram estudados. $\bigcirc$ artigo que trata desta ordem, pertencente à classe Mammalia, 
traz importantes informações sobre a diversidade e a ecologia das espécies coletadas. Os aspectos fitogeográficos e paisagísticos da região justificam a relevância da pesquisa sobre os mamíferos voadores. O estudo, além de inventariar as espécies existentes, avaliou as espécies ameaçadas e as que poderão permitir, aos gestores do Parque, o monitoramento dos ambientes, pois algumas espécies de morcegos são consideradas bioindicadores.

A diversidade de mamíferos, descrita no artigo seguinte, é subestimada, segundo os autores, pois seriam necessários longos períodos de campo para a realização de pesquisas mais aprofundadas. No entanto, os resultados permitem avaliar a importância da fauna de mamíferos não voadores para o plano de manejo, considerando que seja realizado um monitoramento regular da diversidade registrada de mamíferos. Espécies ameaçadas e com risco de extinção foram catalogadas na área do Parque, assim como espécies endêmicas para a Amazônia.

Os dois últimos artigos tratam das populações tradicionais em uma das comunidades locais e do planejamento turístico do Parque. $\bigcirc$ grupo tradicional, objeto do artigo, vive na comunidade Santa Cruz e é descrito com base nos levantamentos da geografia humana, área de formação da autora, e na sua vivência na própria comunidade. É possível, com esta leitura, tomar conhecimento dos modos de vida de uma comunidade amazônica e de suas relações com o ambiente, por meio da história da ocupação e do uso da terra. No entanto, o texto não descreve se há uma relação da comunidade com o Parque Martírio-Andorinhas.

O último artigo trata da situação do turismo na região e de suas perspectivas frente à implantação de uma unidade de conservação. Os autores realizaram levantamentos in loco para o delineamento do perfil do turista, que, somados às observações e às avaliações ambientais, determinaram um forte potencial turístico para a região e o mau uso deste potencial. Os autores vislumbram que, para a região obter os rendimentos propostos em empreendimentos turísticos advindos de unidades de conservação, é necessário implantar infraestrutura adequada na região. $\bigcirc$ texto contém ilustrações e mapas de utilização de trilhas já conhecidas, revelando para o leitor os potenciais turísticos locais.

Publicado em 2008 com resultados de pesquisas realizadas entre 1998 e 2002, o livro aponta aos gestores ambientais vários indicadores para o manejo de uma das unidades de conservação mais relevantes do Pará. Sentese a ausência de estudos da fauna ictiológica da região do Parque e das comunidades do interior da unidade, o que não descaracteriza a importância do livro. Os artigos publicados são relevantes para a conservação da biodiversidade e para o planejamento da unidade de conservação, na medida em que cada texto expressa uma proposta para o manejo, definida na conclusão das pesquisas. Ressalta-se que o Parque Estadual da Serra dos Martírios-Andorinhas teve seu Plano de Manejo elaborado em 2006 (Sectam, 2006). Muitos autores que participaram dos levantamentos iniciais - e que participam do livro - estão citados no Plano, mas ainda podem ser sentidas dificuldades na interrelação entre pesquisa e gestão.

\section{REFERÊNCIA}

SECTAM. Secretaria de Estado da Ciência, Tecnologia e Meio Ambiente do Pará. Plano de Manejo do Parque Estadual Serra dos Martírios-Andorinhas. 2006. Disponível em: <http://www. sectam.pa.gov.br/>. Acesso em: jan. de 2008. 